\title{
Maxing out the axillary artery for arterial cannulation in acute type A dissection
}

\author{
W. Brent Keeling, MD, and Edward P. Chen, MD
}

\author{
From the Division of Cardiothoracic Surgery, Emory University, Atlanta, Ga. \\ Disclosures: Authors have nothing to disclose with regard to commercial support. \\ Received for publication May 25, 2016; accepted for publication May 26, 2016; available ahead of print June 16, \\ 2016 \\ Address for reprints: Edward P. Chen, MD, Division of Cardiothoracic Surgery, Emory University School of Med- \\ icine, 5665 Peachtree Dunwoody Rd, Suite 200, Atlanta, GA 30342 (E-mail: epchen@emory.edu). \\ J Thorac Cardiovasc Surg 2016;152:808-9 \\ 0022-5223/\$36.00 \\ Copyright (c) 2016 by The American Association for Thoracic Surgery \\ http://dx.doi.org/10.1016/j.jtcvs.2016.05.048
}

Over the past decade, many reports have surfaced in the surgical literature detailing the safety and utility of right axillary artery cannulation strategies during aortic surgery. ${ }^{1-3}$ Researchers have demonstrated equivalent neurologic outcomes after major aortic reconstructions with open distal anastomoses. Cannulation of the right axillary artery has been shown to be safe and facilitates antegrade cerebral perfusion techniques.

Persistent questions continue to surround right axillary artery cannulation strategies: What if the right axillary artery is damaged or dissected? How often is the innominate involved in the dissection? Can it still be used for arterial inflow? What if just the innominate is involved in the disease process? Rylski and colleagues ${ }^{4}$ attempted to answer most of these in their multicenter examination of dissected innominate arteries during type A dissection repair. More than 400 patients were included for analysis in the study, and $45 \%$ of them had some degree of dissection within their innominate artery. Outcomes based on cannulation strategy (right axillary artery vs non-right axillary artery) were compared for the 186 patients with an innominate dissection. Most important, the researchers found no difference in neurologic outcomes or rates of inhospital mortality between patients who underwent right axillary artery cannulation and patients managed with other cannulation strategies. Although the numbers were small, the authors also detailed successful right axillary arterial cannulation in 8 patients who had involvement of their right axillary involvement in the dissection process. These data are encouraging and novel. The layers of the axillary artery can be successfully reapproximated and safely used for arterial inflow, a strategy used in our own institution with satisfactory results when this problem is encountered.

However, this research generated many unanswered questions. Why did the group who underwent right axillary artery cannulation require a higher number of supplemental arterial cannulation sites $(30 \%$ vs $9 \%)$ ? Surgeon preference was

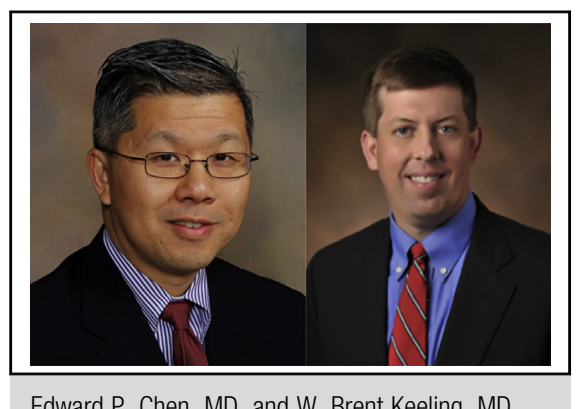

Edward P. Chen, MD, and W. Brent Keeling, MD

\section{Central Message}

Little data exist regarding the safety and efficacy of cannulating the right axillary artery in the setting of a dissected innominate artery for type A dissection repair. The authors present a series detailing the safety of this practice.

See Article page 801

cited as the reason in half of these $30 \%$ of patients, but this alone does not help to explain the disparity. Although the perfusion strategies were well described before the initiation of circulatory arrest, the authors failed to mention alterations in perfusion strategy after completion of the open distal aortic anastomosis. Most surgeons would advocate for reestablishment of true antegrade flow across the great vessels via cannulation of a side branch off the ascending graft, but these details were unclear. Given that this was a multiinstitutional study, perfusion practices varied, thus introducing further inequities in practice and likely in outcomes.

Nevertheless, this study remains important for the reasons stated. According to the authors, cannulation of the right axillary artery in the setting of an innominate dissection is safe and, in the absence of an elevated line pressure, effective. The authors also establish that reapproximation of a dissected right axillary artery for the purposes of cannulation is feasible. Rylski and colleagues ${ }^{4}$ have yielded additional insight making right axillary artery cannulation possible for expanded indications.

\section{References}

1. Comas GM, Leshnower BG, Halkos ME, Thourani VH, Puskas JD, Guyton RA, et al. Acute type a dissection: impact of antegrade cerebral perfusion under moderate hypothermia. Ann Thorac Surg. 2013;96:2135-41.

2. Halkos ME, Kerendi F, Myung R, Kilgo P, Puskas JD, Chen EP. Selective antegrade cerebral perfusion via right axillary artery cannulation reduces morbidity and mortality after proximal aortic surgery. J Thorac Cardiovasc Surg. 2009; 138:1081-9. 
3. Leshnower BG, Kilgo PD, Chen EP. Total arch replacement using moderate hypothermic circulatory arrest and unilateral selective antegrade cerebral perfusion. J Thorac Cardiovasc Surg. 2014;147:1488-92.
4. Rylski B, Czerny M, Beyersdorf F, Kari FA, Siepe M, Adachi H, et al. Is right axillary artery cannulation safe in type A aortic dissection with involvement of the innominate artery? J Thorac Cardiovasc Surg. 2016;152:801-7.

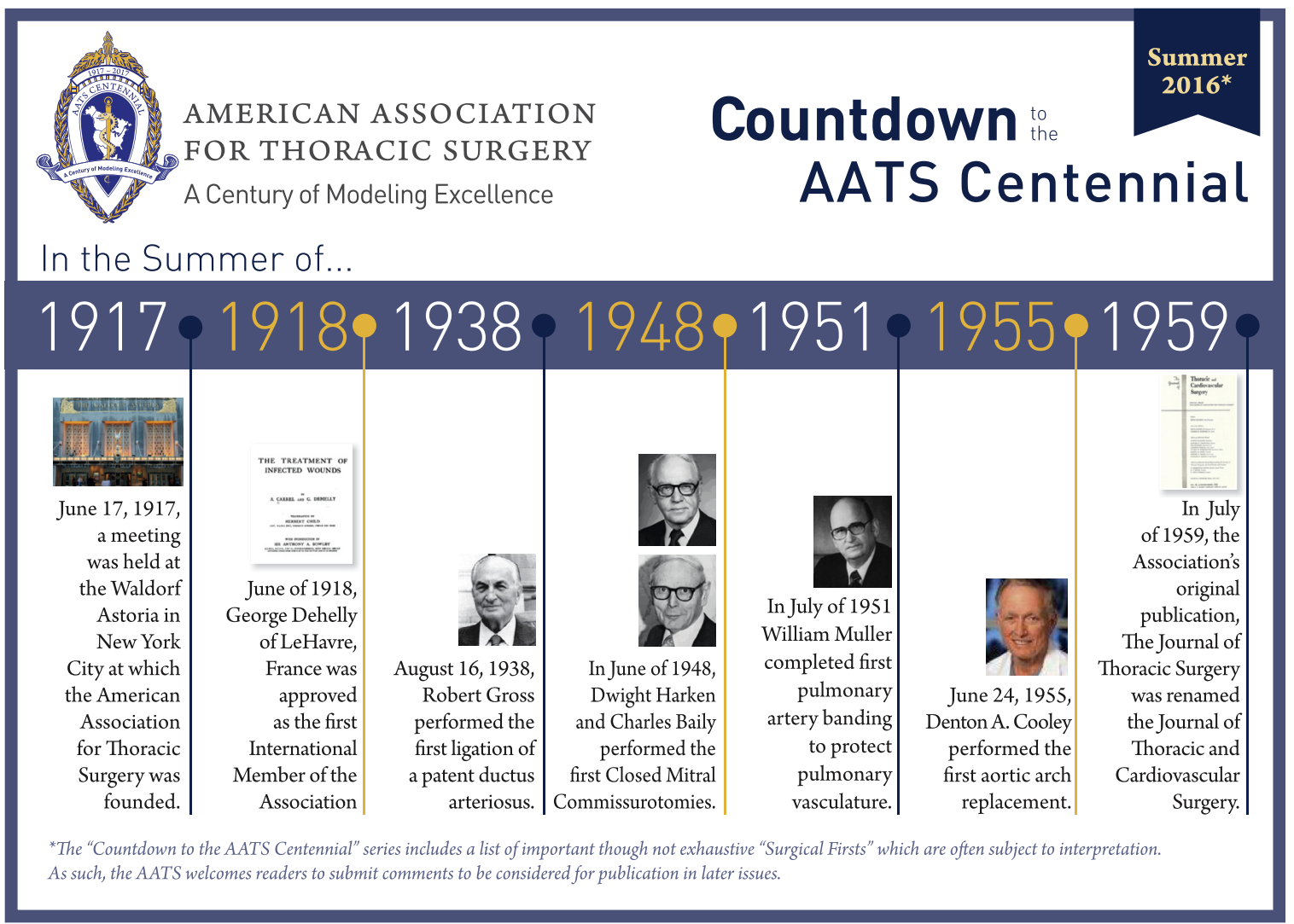

